\title{
Erlang could have told you so - a case study of health policy without maths
}

\begin{abstract}
Little consideration is given to the operational reality of implementing national policy at local scale. Using a case study from Norway, we examine how simple mathematical models may offer powerful insights to policy makers when planning policies. Our case study refers to a national initiative requiring Norwegian municipalities to establish acute community beds (municipal acute units or MAUs) to avoid hospital admissions. We use Erlang loss queueing models to estimate the total number of MAU beds required nationally to achieve the original policy aim. We demonstrate the effect of unit size and patient demand on anticipated utilisation. The results of our model imply that both the average demand for beds and the current number of MAU beds would have to be increased by $34 \%$ to achieve the original policy goal of transferring 240000 patient days to MAUs. Increasing average demand or bed capacity alone would be insufficient to reach the policy goal. Day-to-day variation and uncertainty in the numbers of patients arriving or leaving the system can profoundly affect health service delivery at the local level. Health policy makers need to account for these effects when estimating capacity implications of policy. We demonstrate how a simple, easily reproducible, mathematical model could assist policy makers in understanding the impact of national policy implemented at the local level.
\end{abstract}




\section{Introduction}

Researchers often criticize health policy makers for developing policies that are insufficiently evidence based. On the other hand, policymakers often criticize researchers for being insufficiently aware of policy processes and requirements when conducting research $(1,2)$. More conventional forms of research may not address issues of day to day operations or implementation that policy makers need answered. As a result, policy makers often face the difficult task of making capacity or resource related decisions based on limited information.

Little consideration is given to the operational implications of implementing national policy at local level. Variation in the demand for health services (i.e. variation in the number of patient referred or in lengths of stay) can profoundly affect the capability of the health system to meet this demand. If policy makers do not understand the effect of inevitable peaks and troughs in demand when estimating capacity requirements, they may design systems that are chronically unable to meet demand. This in turn may lead to unacceptably high numbers of patients being turned away, lying in corridors or waiting considerable time for necessary intervention (3) .

In the context of capacity planning related to unplanned inpatient care, the problem presented by variability is that, when there is a peak in demand that exceeds capacity (due to higher than average referrals and/or longer than average patient stays), patients cannot be admitted and receive care elsewhere. Conversely, when there is a trough in demand that falls below capacity (due to fewer than average arrivals and/or shorter than average patient stays), some capacity goes unused.

A related problem often neglected when national policy is implemented at the local level is that smaller units are far more susceptible to variation in demand than larger units (3). This can lead to lower utilisation rates than policy makers expect. Unmet expectations may lead to frustrations and misplaced accusations of low productivity.

The phenomena above are well described in operational research (OR) - an applied form of research that attempts to understand real world problems and how to solve them using mathematical approaches including queue theory (4). The Danish mathematician Erlang introduced the concept of "queue 
theory" in the early twentieth century (5). The practical purpose behind his theory was to calculate the number of switchboard operators required to answer a certain level of incoming calls within a specified time limit.

It comes as no surprise that the theory has applications beyond telecommunications. In health care, queue theory has been used for a wide range of issues, including health system design, capacity planning, resource allocation, optimisation and scheduling (6). That said, OR methods are not widely used to inform health care policy (7-9). There is reason to believe that OR can assist policy makers in implementing national health policy by given them a means to explore the consequences of proposed policy changes at the local level and by improving their understanding of the disruptive effects of local variability in demand $(6,10-14)$. In this study, we use a case from Norway to demonstrate how simple OR models may offer powerful insights to policy makers.

In 2016, Norway made the provision of acute community beds (municipal acute units or MAUs) mandatory for all 400+ municipalities $(15,16)$. MAUs were intended to offer an alternative to hospital admission. They were not, however, intended to be used as step down facilities for patients already admitted to hospital (17). The original policy goal stipulated a transfer of approximately 240000 patient days per year from hospitals (18) to MAUs corresponding to a tenth of medical emergency admissions. As municipal populations vary considerably (from 206 to 672000 ), the number of MAU beds required by each municipality was expected to vary accordingly (19).

We use queue theory to estimate the total number of MAU beds required to achieve the national policy goal. We demonstrate how local unit size, defined as the number of MAU beds per unit, may affect utilisation and cause difficulties in achieving policy aims. In particular, we highlight how variability in referral rates and/or lengths of stay at the local level can have a big impact on achieving national policy goals.

\section{Materials and methods}

To illustrate how simple analytical models may be used to inform policy development, we wanted to mimic a typical situation for policy makers with little empirical evidence available prior to 
implementation. Our assumptions regarding policy goals and total planned capacity were thus derived from the policy documents originating prior to introduction of MAUs (15-17). Based on the national policy aim of 240000 patient days and making no adjustment for variability in the demand for services, we calculated that the government intended to establish 658 beds $(240000 / 365)$ nationally

The only post-hoc data we used related to the distribution of unit sizes, which was based on the number of beds reported by 206 MAUs for 2017, as shown in Figure 1 (20). MAUs appear to have used population based estimates of demand calculated by the Directorate of Health to determine the number of beds they should establish $(18,21)$. Given that the population in each municipality has been relatively unchanged since 2012 we considered it reasonable to use empirical data from 2017 as a proxy for policy makers' intentions in 2012.

We used the so-called Erlang loss model to analyse the impact of random variation in demand for beds on the flow of patients through MAUs. The model estimates the proportion of patients that would be turned away (hereafter referred to as the turn-away rate) when the average demand for beds is at a particular level, for a unit of a given capacity. The model assumes that the number of patients referred follows a Poisson distribution, meaning that the likelihood that a patient is referred at any time is independent of the time elapsed since the previous referral. It also assumes that the system modelled has a finite capacity i.e. the maximum number of beds cannot be exceeded. As MAUs are intended for acute patients, we also assume that no queue could form i.e. when the MAU is at full capacity new patients are turned away and admitted to hospital.

In the long term, it makes no difference if the average number of referrals per day is 2 and their average length of stay is 6 days or there is an average of 4 referrals a day with a length of stay of 3 days. In both cases the average demand for beds would be 12 patient days ( $2 * 6$ and $3 * 4)$, which means that if all patient referrals were accepted, the number of beds in use would fluctuate randomly around a long term average of 12 in either case. This enables us to analyse the number of patient days that could potentially be moved from the hospital sector to the MAUs, without having to consider the 
details of arrival frequencies and length of stay. This becomes apparent when we take a closer look at the equation for the Erlang loss function.

For a given capacity $n$, and an average demand $d$, the Erlang loss function $B(n, d)$ is given by

$$
B(n, d)=\frac{d^{i}}{n ! \sum_{i=0}^{n} d^{i} / i !} .
$$

$\mathrm{B}(\mathrm{n}, \mathrm{d})$ is the proportion of the time that all $n$ beds will be in use, given an average demand of $d$. Since we assume that referrals occur at random times and patients are turned away if all the beds are in use, $B(n, d)$ can also be interpreted as the turn away rate. In the long run, $[1-B(n, d)]$ gives the proportion of referrals that are admitted to the MAU, meaning that the average number of beds in use is $d *$ $[1-B(n, d)]$

Activity can be defined as patient days delivered (23), and according to our model, the expected number of patient days $X(n, d)$ that are delivered through a year for an MAU with $\mathrm{n}$ beds and demand $\mathrm{d}$ is:

$$
X(n, d)=365 * d *[1-B(n, d)]
$$

We modelled the impacts of different scenarios on utilisation and capacity requirements:

1. baseline scenario with 658 beds distributed according to the empirical distribution, assuming an average demand equal to the capacity for each MAU

2. as scenario 1 , but average demand doubled

3. as scenario 1, but unit capacity increased to achieve $90 \%$ of policy goal

4. as scenario 1, but average demand and unit capacity increased proportionately to meet policy goal

The scenarios are described in further detail below.

\section{Scenario 1:}


This scenario was designed to estimate the effect of the original policy in MAU patient days delivered per year. We used the empirical distribution of MAU sizes shown in Figure 1 as a blueprint for the distribution that could have been expected at the time. As the total number of beds in the empirical distribution was 706 and the number of beds implied by the policy documents was 658 , we multiplied the sizes in Figure 1 by a factor (658/706), which ensured that their sum was 658 . This rescaled distribution included decimal (non-integer) numbers of beds, which are difficult to interpret and do not fit the Erlang model. We devised an algorithm that allowed us to approximate the rescaled distribution as closely as possible to the original distribution using positive integers as MAU sizes. This allocation algorithm is reported in the appendix. We assumed that each MAU had an average demand equal to its size $(d=n)$ and used Eq. 2 to estimate their annual number of patient days and summed these numbers over the 206 units.

\section{Scenario 2:}

In scenario 1 the average demand for beds was equivalent to the unit capacity i.e. the number of beds in the unit. In scenario 2 we looked at the effect on utilisation of substantially increasing the average demand for beds. Such an increase could be achieved by increasing referral rates, for example by broadening the criteria for MAU admission. We chose to double demand to represent an extreme scenario $(d=2 n)$. The distribution of unit size remained the same as scenario 1 and the same calculations were performed.

\section{Scenario 3:}

In this scenario all input parameters were the same as scenario 1 except capacity. Keeping demand the same as in the first scenario, we calculated the additional number of MAU beds required to deliver $90 \%$ of the target 240000 patient days per year. The allocation algorithm (see appendix) was used to distribute this additional bed capacity across our hypothetical MAUs. The total number of beds was increased from 658 until the $240000 * 0.9=216000$ patient days was reached.

\section{Scenario 4:}


In scenario 4 we increased average demand and unit capacity proportionately, until the policy target of 240000 patient days was achieved. As in the previous examples the allocation algorithm was used to determine the distribution of unit sizes as the total number of beds was increased.

\section{Results}

In this section we present the results of applying our Erlang loss model to different scenarios representing different degrees of variability and scale (national and local).

Scenario 1 - baseline model of the original policy decision

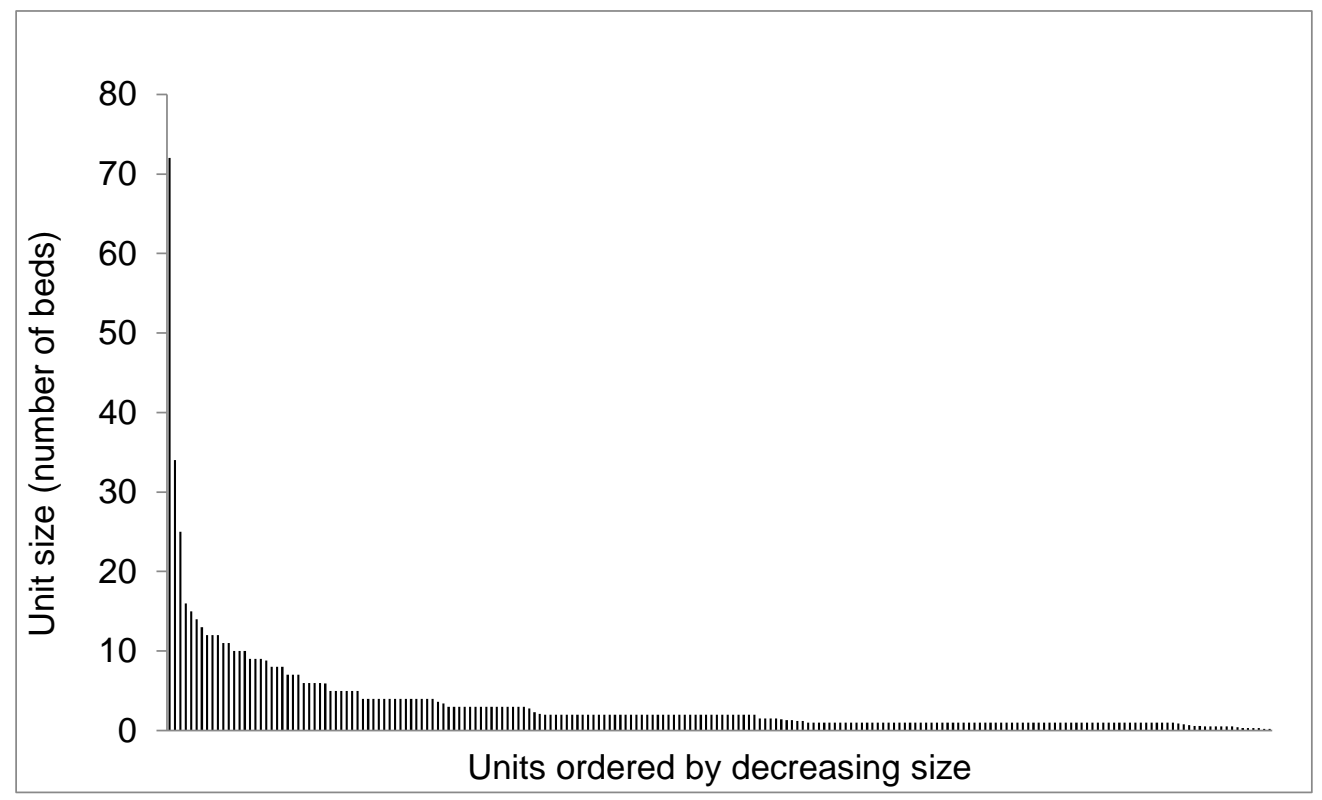

Figure 1. Empirical distribution of unit size ordered by decreasing size

Figure 1 shows the distribution of unit size in 2017 (20). The data show that $67 \%$ of MAUs have fewer than 3 beds per unit, with $42 \%$ of units having 1 bed (this number includes also units reporting noninteger values of beds, including those reporting less than 0.5 beds/unit - likely to be due to MAU function being shared between municipalities or with other functions). The three largest units with 72 , 34 and 25 beds respectively are MAUs in major cities.

Under this scenario, average utilisation was $71 \%$, and $29 \%$ of patients were turned away. As a result, the expected number of patient days delivered by this scenario was only 170696 . This value fell short 
of the desired outcome of 240000 patient days by $29 \%$. In the model, larger units have higher utilisation rates than smaller units and lower probabilities of turning patients away. This can be seen in Figure 2 where the graph on the left shows the relationship between increasing unit size and the percentage of patients turned away. The graph on the right shows the relationship between utilisation and increasing unit increasing size. The blue bars represent scenario 1 and the orange bars scenario 2 .

\section{Scenario 2 - with demand doubled}

We doubled the average demand for beds which can be interpreted as doubling the referral rate, whilst keeping the length of stay constant. As a result, the bed utilisation increased to $85 \%$ but at the cost of turning more patients away, with the turn-away rate increasing to 57\%. The expected number of patient days delivered increased to 204261 but still fell short of the policy aim by 15\%. In Figure 2, the graph on the left shows the effect of doubling demand on the percentage of patients turned away for units of increasing size. The graph on the right shows the effect of doubling demand on utilisation, for units of increasing size. The orange bars show the change in turn-away rates and utilization when average demand is doubled. We can see that doubling average demand increases utilisation rates with the effect being more pronounced in smaller units. The probability of turning patients away also increases, this time with a more pronounced effect in larger units.
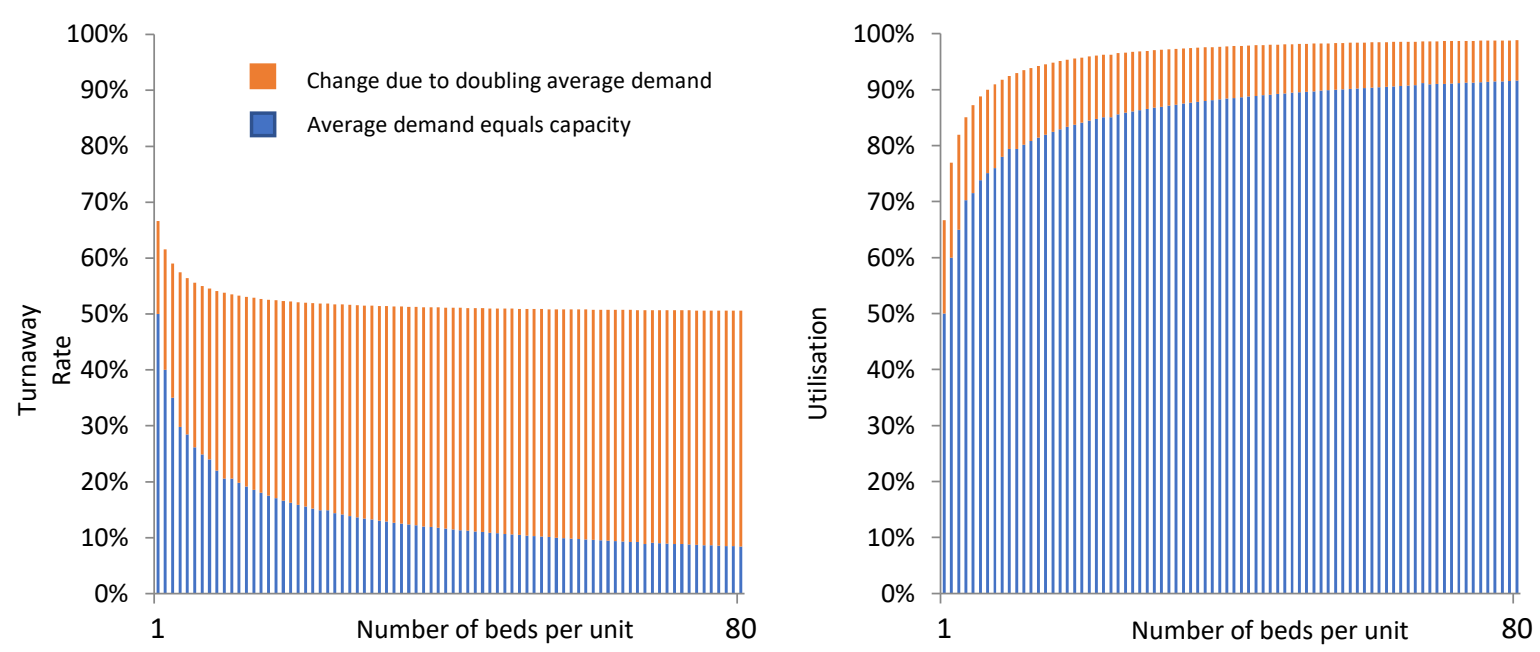

Figure 2. Effect of increasing average demand on utilisation and turn away probability for a given unit size. 


\section{Scenario 3- capacity increased to achieve $90 \%$ of policy goal}

We used Scenario 3 to approximate the additional number of beds required to achieve $90 \%$ of the original policy goal, assuming all other conditions were equivalent to Scenario1. This corresponds to a turn-away rate of $10 \%$. We found that we needed to increase the total number of beds to 1045 in order to deliver the 216000 patient days of activity. This represented a $59 \%$ increase in bed capacity when compared to the estimate of 658 beds for a system with no variability.

Scenario 4- average demand and unit capacity increased proportionately to meet policy goal

In Scenarios 2 and 3 we studied the effects of increasing either average demand or unit capacity. In Scenario 4 we increased both demand and unit capacity proportionately. We estimated that average demand and the total number of beds needed to increase by $34 \%$ to 884 in order to achieve the policy goal of 240000 patient days.

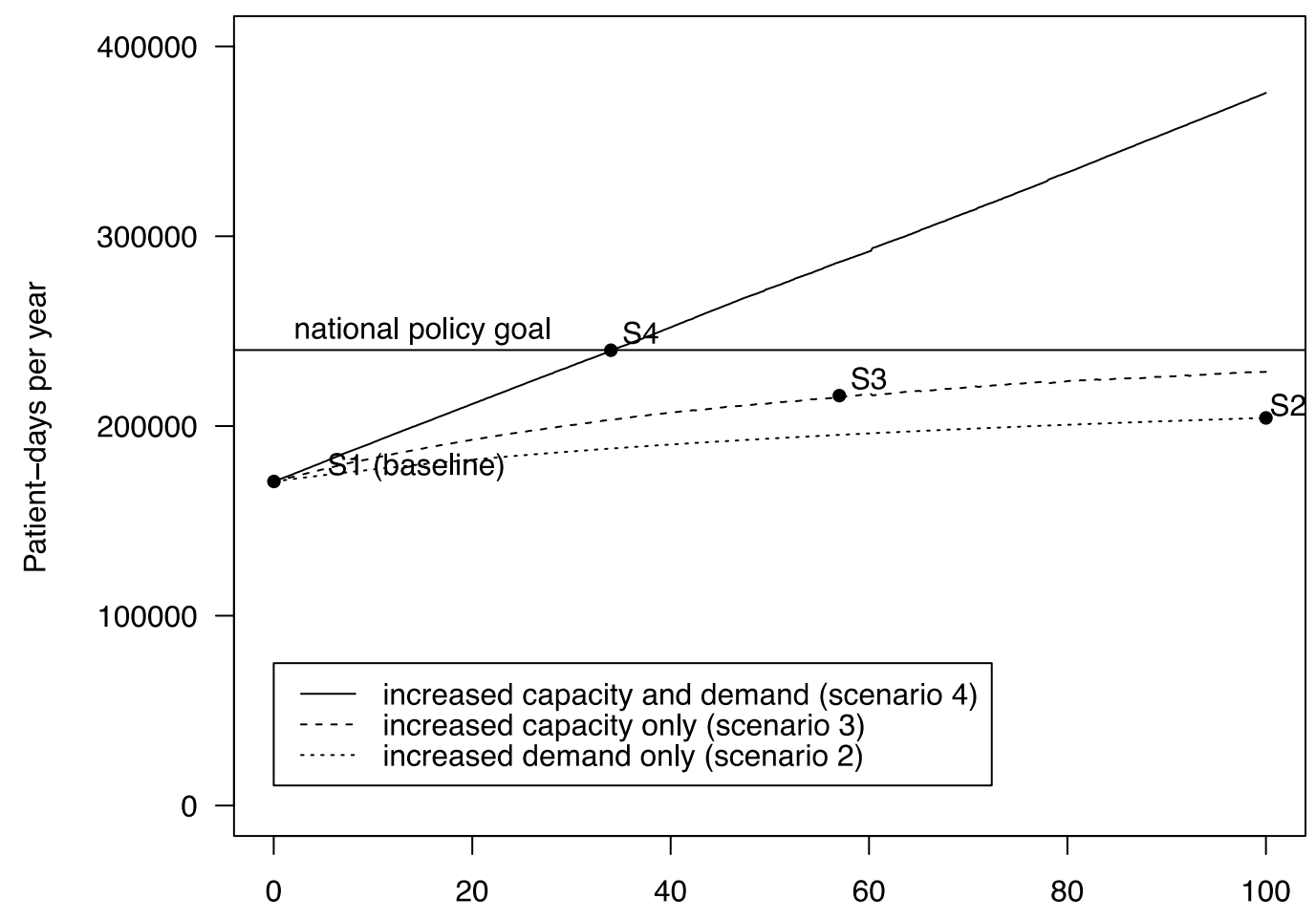

Percentage increase in capacity and/or average demand

Figure 3. The impact of different policy levers. Scenarios $1-4$ are represented graphically as points S1- S4. 
In Figure 3, the Y axis represents the annual number of patient days delivered under each scenario.

The $\mathrm{X}$ axis represents a percentage increase in either average demand (as in Scenario 2) or bed capacity (as in Scenario 3) or both (as in Scenario 4). The solid line represents Scenario 4 which is the only scenario where the policy goal is achieved by increasing both average demand for beds and bed capacity by $34 \%$. The dashed line in the middle represents Scenario 3 where $90 \%$ of the policy goal is attained by dramatically increasing the number of beds. The dotted line at the bottom corresponds to Scenario 2 which, of the three, delivers the least number of patient days even at the extreme of doubling the average demand for beds ( $100 \%$ increase). As such we see that both capacity and demand must be increased to achieve the policy goal.

\section{Discussion}

We carried out a post-hoc analysis of the national roll out of municipal acute units in Norway. Our analyses suggest that Norwegian policy makers substantially underestimated the bed capacity necessary to achieve the original policy goal. Our example highlights the disconnect between national policy and local implementation, where assumptions that hold true at the aggregate level, are no longer valid when disaggregated at the local level.

Qualitative research suggests that municipalities used the estimates in the national guidelines to calculate the number of beds required (22). When devising their estimates of the number of MAU beds required, national authorities appear to have fallen into a common trap; they did not consider how variation in referral and discharge rates and variation in unit size may affect bed utilisation. The latter is an important consideration given the large number of sparsely populated municipalities that require few MAU beds.

MAUs have received a lot of criticism for having consistently low utilisation rates (21). This is in part explained by factors contributing to under use of MAU beds such as lack of awareness of or scepticism towards these new units amongst referring practitioners $(21,23)$. Another explanation, and the one most likely to be overlooked, may be the effect of unit size on their intrinsic ability to achieve 
higher rates of utilisation in the face of variation. Queue theory implies that at a given level of utilisation, larger units experience economies of scale i.e. they can have higher utilisation rates while turning away a lower proportion of patients than small units (11). If most MAUs are very small units i.e. less than 3 beds, our findings suggest that the average utilisation would be $60 \%$ or less which is far lower than most hospitals. The OECD average for hospital utilisation is around $76 \%$, though Norwegian hospitals have traditionally been higher $(24,25)$. Policy makers unaware of the impact of unit size on utilisation may be more likely to have unrealistic expectations of what MAUs are capable of delivering.

Following on from this, it is worth considering whether criticism coupled with unrealistic expectations encourages counterproductive behaviours at MAUs. These could include admitting patients who would not otherwise be admitted to hospital, in order to improve utilisation. Paradoxically, this may result in a situation where patients eligible for admission to MAU are turned away due to lack of available beds. Recent studies lend weight to this hypothesis; Swanson and Hagen showed a decrease of only $1.2 \%$ in hospital admissions following the introduction of MAUs (26). A possible explanation, identified by Leonardsen, is that referring health care practitioners perceive MAUs less as a substitute to hospital admission and more as a brand new type of service (23). Alternatively, the implicit assumption that demand for hospital beds is well defined could be incorrect. This would mean the capacity freed up within hospitals by transferring patient days to MAUs would promptly be filled by other patients. This could happen if admitting practices of general practitioners were influenced by their perception of how full the local hospital was. For example, GPs might be more inclined to refer less severely ill patients if they considered the hospital to be less busy.

\section{Strengths and weakness of our study}

An obvious strength of our modelling is that it can be easily reproduced, and its assumptions easily understood by policy makers and practitioners. In addition, it is not dependent on large quantities of data nor does it require complex programming skills to build and deploy. 
It is, however, important to acknowledge that mathematical models are based on simplified assumptions of real life. The most obvious weakness of the queueing model is the assumption that a patient is equally likely to arrive at any point in time. Most real-life arrival processes in health care experience more variation than is accounted for here - there may be fluctuations in arrival rates over the course of the week, months of the year and times of the day. For example, a hospital ward might have fewer new admissions at weekends than during the week. As such, the results of our models are likely to be overly optimistic with respect to average utilisation. In real life, where the average demand for beds varies, peak periods will give increased utilisation rates but at the expense of turning more patients away. Similarly, quieter periods will result in lower utilisation of beds but fewer patients being turned away. The higher turn-away rate during busy periods outweighs the lower rate in less busy periods. Using a simulation model would have allowed us to account for time-varying arrival rates but the key messages would be the same.

Our empirical distribution did not indicate whether MAU beds were located in independent units or were ring-fenced beds in larger units primarily serving another function. It is not uncommon for MAU beds to be located in nursing homes. This could have implications for the actual utilisation levels of such beds, particularly if the ring-fencing was not absolute and the beds could also be used for other purpose. We have also not accounted for situations where units may temporarily increase capacity in periods of high demand.

MAU beds form a small proportion of the total number of beds managed by municipalities. Many MAUs are collocated with other municipal entities who also admit patients on a short-term basis, such as short term rehabilitation wards. Whilst these wards should address the needs of a different group of patients than those eligible for MAU admission, it is often the case that available beds may be used for other purposes if the need arises. It is likely that this form of pragmatic buffering within municipal health services may be helpful under certain circumstances, but we did not attempt to factor this into our analyses. In future analyses this could be incorporated into a simulation model. Simulation modelling could be used to account for the variation in arrivals rates mentioned earlier. In addition, 
such models can be used to explore the impacts of policy relevant scenarios such as merging MAUs on utilisation or altering patient flows.

\section{Conclusions}

To our knowledge there has been no prior evaluation of the number of MAU number of beds required nationally. Our study may be interesting for policy makers considering how to improve or adjust future policy concerning MAUs. Perhaps more importantly it demonstrates how simple analyses can provide important insights even when data is lacking.

It is not unusual that health care policy is based on inaccurate or unfeasible premises - or a disregard for how the policy will play out at the local level. This may be due to several reasons including a lack of available evidence, political or time-related pressures. When evaluating policies that may not have delivered the expected result, it is important to determine whether the fault lies with the initial policy aim, which may be have been unrealistic, or the policy implementation, which may have been suboptimal.

Even though the mathematics involved is not particularly advanced, the types of analyses we carried out are not commonly part of policy development. This may be due to a lack of awareness, ability or concern that such models may be regarded with suspicion. Our results demonstrate that there is a strong case for bringing more maths into policy. Decision makers should be more aware of the options available to them when asking for information to inform policy decisions. 


\section{References}

1. Ellen ME, Lavis JN, Horowitz E, Berglas R. How is the use of research evidence in health policy perceived? A comparison between the reporting of researchers and policy-makers. Health Research Policy and Systems. 2018 Jul 20;16(1):64.

2. Haynes AS, Derrick GE, Chapman S, Redman S, Hall WD, Gillespie J, et al. From "our world" to the "real world": Exploring the views and behaviour of policy-influential Australian public health researchers. Social Science \& Medicine. 2011 Apr 1;72(7):1047-55.

3. Green LV, Nguyen V. Strategies for cutting hospital beds: the impact on patient service. Health Serv Res. 2001 Jun;36(2):421-42.

4. Crowe S, Turner S, Utley M, Fulop NJ. Improving the production of applied health research findings: insights from a qualitative study of operational research. Implement Sci. 2017 Sep $8 ; 12(1): 112$.

5. Gross D, Shortle JF, Thompson JM, Harris CM. Fundamentals of Queueing Theory. 4th ed. Wiley; 2009.

6. Lakshmi C, Sivakumar AI. Application of queueing theory in health care: A literature review. Operations Research for Health Care. 2013 Mar;2(1-2):25-39.

7. Brailsford SC, Harper PR, Patel B, Pitt M. An analysis of the academic literature on simulation and modelling in health care. J Simulation. 2009 Sep 1;3(3):130-40.

8. Jun GT, Morris Z, Eldabi T, Harper P, Naseer A, Patel B, et al. Development of modelling method selection tool for health services management: From problem structuring methods to modelling and simulation methods. BMC Health Serv Res. 2011 May 19;11:108.

9. Naseer A, Eldabi T, Young TP. RIGHT: A toolkit for selecting healthcare modelling methods. J Simulation. 2010 Mar 1;4(1):2-13.

10. Palmer R, Fulop NJ, Utley M. A systematic literature review of operational research methods for modelling patient flow and outcomes within community healthcare and other settings. Health Systems. 2018 Jan 2;7(1):29-50.

11. Green L. Queueing Analysis in Health Care | SpringerLink. In: Patient Flow: Reducing Delay in Healthcare Delivery [Internet]. New York, NY: Springer Science+Business Media; 2013 [cited 2018 Aug 24]. (International Series in Operations Research \& Management Science). Available from: https://link.springer.com/chapter/10.1007/978-1-4614-9512-3_15

12. McManus ML, Long MC, Cooper A, Litvak E. Queuing Theory Accurately Models the Need for Critical Care Resources. Anesthes. 2004 May 1;100(5):1271-6.

13. Utley M, Gallivan S, Treasure T, Valencia O. Analytical methods for calculating the capacity required to operate an effective booked admissions policy for elective inpatient services. Health care management science. 2003;6(2):97-104.

14. Foster EM, Hosking MR, Ziya S. A Spoonful of Math Helps the Medicine Go Down: An Illustration of How Healthcare can Benefit from Mathematical Modeling and Analysis. 2010;11.

15. Helse-og omsorgsdepartementet. Meld. St. 16 (2010-2011). Nasjonal helse- og omsorgsplan (2011-2015) [Internet]. Oslo, Norway: Helse- og omsorgsdepartement; 2011 Apr [cited 2018 
Sep 15]. Report No.: 16. Available from: https://www.regjeringen.no/no/dokumenter/meld-st-1620102011/id639794/

16. Norwegian Ministry of Health and Care Services. Report No. 47 (2008-2009) to the Storting. The Coordination Reform Proper treatment - at the right place and right time [Internet]. Oslo: Norwegian Ministry of Health and Care Services; 2009 Jun [cited 2017 Apr 18]. Report No.: 47. Available from:

https://www.regjeringen.no/contentassets/d4f0e16ad32e4bbd8d8ab5c21445a5dc/no/pdfs/stm200 820090047000dddpdfs.pdf

17. Helsedirektoratet. Notat av 5.4.2011 - Kostnadsberegning ø-hjelp døgnopphold i kommunene [Internet]. Helsedirektoratet; 2011 [cited 2018 May 24]. Available from:

https://helsedirektoratet.no/Documents/Samhandlingsreformen/Rapport-kostnadsberegninger$\%$ C3\%B8-hjelp.pdf

18. Helsedirektoratet. Kommunenes plikt til oyeblikkelig hjelp dognopphold veiledningsmateriell [Internet]. Oslo, Norway: Helsedirektoratet; 2012 Feb [cited 2017 May 4]. Report No.: 02/ 2012. Available from: https://helsedirektoratet.no/Lists/Publikasjoner/Attachments/133/Kommunenesplikt-til-oyeblikkelig-hjelp-dognopphold-veiledningsmateriell.pdf

19. Statistics Norway. Population. Table 05231: Estimated population per December 31st, and population growth during the year 2009 - 2018 [Internet]. www.ssb.no. [cited 2019 Jan 14]. Available from: http://www.ssb.no/en/statbanken/statbank/table/05231/

20. Helsedirektoratet. Status for kommunalt døgntilbud for øyeblikkelig hjelp 2017 [Internet]. Oslo, Norway: Helsedirektoratet; [cited 2018 Sep 14]. (Analysenotat). Report No.: 07 /2018. Available from:

https://helsedirektoratet.no/Documents/Nyheter/Status\%20for\%20kommunalt\%20d\%C3\%B8gnt ilbud\%20for\%20\%C3\%B8yeblikkelig\%20hjelp\%202017.pdf

21. Skinner MS eter. Skeptiske leger og tomme senger? Bruk av kommunale akutte døgnplasser [Internet]. Senter for omsorgsforskning, øst; 2015 [cited 2018 Sep 14]. (Senter for omsorgsforsknings rapportserie). Report No.: 10/2015. Available from: https://brage.bibsys.no/xmlui/bitstream/id/384840/rapport_10_2015_tomme\%20senger_web.pdf

22. Skinner MS. Døgnåpne kommunale akuttenheter: En helsetjenestemodell med rom for lokale organisasjonstilpasninger [Municipal acute bed units: a national health service model with scope for local adaptation]. Tidsskrift for omsorgsforskning. 2015;1(2):131-144.

23. Leonardsen A-CL, Del Busso L, Grøndahl VA, Ghanima W, Jelsness-Jørgensen L-P. General practitioners' perspectives on referring patients to decentralized acute health care. Fam Pract. 2016 Dec 1;33(6):709-14.

24. Den norske legeforening, Sykehus. Overbelegg i norske sykehus - en trussel mot pasientsikkerheten (1/2015) [Internet]. Den norske legeforening; 2015 Apr [cited 2018 Sep 20]. Available from: http://legeforeningen.no/Emner/Andre-

emner/Publikasjoner/policynotater/Policynotater-2015/Overbelegg-i-norske-sykehus--en-trusselmot-pasientsikkerheten/

25. OECD. Occupancy rate of curative (acute) care beds, 2000 and 2015 (or nearest year) [Internet]. OECD; 2017 Oct [cited 2018 Sep 21]. Available from: https://www.oecd-ilibrary.org/socialissues-migration-health/health-at-a-glance-2017/occupancy-rate-of-curative-acute-care-beds2000-and-2015-or-nearest-year_health_glance-2017-graph158-en 
26. Swanson JO, Hagen TP. Reinventing the community hospital: a retrospective population-based cohort study of a natural experiment using register data. BMJ Open [Internet]. 2016 Dec 13 [cited 2017 May 2];6(12). Available from:

http://www.ncbi.nlm.nih.gov/pmc/articles/PMC5168673/ 